\title{
Diet and feeding in the Cape Cobra, Naja nivea
}

\author{
Inshaaf Layloo, Caitlin Smith \& Bryan Maritz
}

\begin{abstract}
It is widely reported that African cobras (genus Naja) are generalist predators, but examination of formal literature yields relatively little evidence of this for most species. Here, we review the diet of cape cobras (Naja nivea) based on examination of museum specimens, an extensive literature review, and social media reported natural history observations. We quantify dietary niche breadth and test the hypothesis that cape cobras are generalist predators. Additionally, we test the hypotheses that diet varies significantly (1) across biomes, and (2) across winter, summer and year-round rainfall regions. We gathered 101 feeding records for cape cobras and based on family-level prey frequencies calculated Levins' measure of niche breadth as $B=6.57$, which we standardised to $B \mathrm{~A}=$ 0.29. We found no association between prey classes and biomes or rainfall region. Our data indicate that cape cobras consume a wide range of vertebrate prey from all four tetrapod classes, including a large number and diversity of snakes. Our findings suggest that cape cobras may be involved in several important ecological processes. Moreover, our study demonstrates the utility and value of collating natural history observations reported on social media platforms.
\end{abstract}

\section{Introduction}

African cobras (genus Naja) are widely reported in the popular literature as generalist predators characterised by broad diets that often include other snakes (Branch, 1998; Marais, 2004). However, examination of the formal literature yields little evidence of this for most species (see Shine et al. 2007). This paucity of formal documentation likely arises as a result of the limited accessibility of specimens available for examination in African collections, the generally low frequency with which many snakes feed and the even lower frequency with which feeding is observed (Greene 1997), as well as the diminishing popularity of natural history studies globally (Greene 2005). However, studies that catalogue and quantify dietary habits of snakes are of foundational importance in understanding questions of evolution, ecology and conservation (Rodríguez- Robles 2002). Moreover, in the case of medically important species, such as cobras, dietary studies can be critical in understanding variation in venom action (Daltry et al. 1998; Barlow et al. 2009) with important implications for ameliorating the impacts of humansnake conflict. 
Cape cobras (Naja nivea) are elapid snakes that occur widely across a variety of biomes in western southern Africa (Branch 1998). Although cape cobras are reported to feed on a wide variety of prey types, including other snakes and birds, the only peer-reviewed study to examine distribution-wide diet (Shine et al. 2007) failed to detect either of these prey types. This is particularly curious given that 1) cobra diets in general are thought to include a large number of snakes (Kgaditse 2016), 2) Phelps (2007) found evidence of snakes in the diet of a population of cape cobras from the south-western cape, and 3) studies that focus on sociable weaver (Philetairus socius) biology have indicated that cape cobras are important predators of birds in at least some systems (Covas et al. 2008).

The apparent disjunction between popular literature and formal literature prompted us to review our knowledge of the diet of cape cobras. Our novel aggregation of dietary data allowed us to examine several hypotheses regarding cape cobra feeding. We quantify dietary niche breadth and test the widely held assertion that cape cobras are generalist predators. The type of prey encountered by foraging snakes may vary by region so we tested the hypotheses that diet varies significantly (1) across biomes, and (2) across winter, summer and year-round rainfall regions.

\section{Materials and methods}

We gathered information regarding the diet of cape cobras from published literature, examination of gut contents of museum specimens, online photographs and social media. We relied primarily on Phelps (2007) and Shine et al. (2007) for summaries of known prey species, but also systematically searched Hockey et al. (2005) specifically for reports of predation of birds by cape cobras. We examined preserved material from the collections of the Ditsong National Museum of Natural History (Tswane), Bayworld (Port Elizabeth), Iziko South African Museum (Cape Town), and the McGregor Museum (Kimberley) (see online supplementary material S1 and S2). We made mid-ventral incisions in the 61 avail- able specimens (39 males; 22 females; snout-vent length (SVL) range: 310-1 $979 \mathrm{~mm}$ ) and removed prey items from the stomach and hindgut for identification. For each dissected individual, we recorded its sex and measured SVL to the nearest millimetre. Prey were identified to the finest possible taxonomic level by examining morphological characteristics (size, colour and overall morphology for recently ingested prey items; tooth and skull morphology for rodents; scale morphology for reptiles) in the context of the specimen's collection location. We additionally drew on recent trends towards the informal reporting of natural history observations on social media by searching the Predation Records for Reptiles and Frogs group (Maritz et al. 2017) on the social media platform Facebook. Finally, we performed ad hoc online searches for images and videos of cape cobras consuming prey.

For each feeding record, we recorded the prey species and the approximate locality of the predation event. Using the locality information, we allocated each record to the biome (fynbos, thicket, savanna, Succulent Karoo, or Nama-Karoo) in which it occurred, and categorised each locality based on whether it receives predominantly winter, summer, or year-round rainfall (Schulze 1997). We quantified family-level prey frequencies across the 
diet records for our aggregated dietary information. Unidentifiable amphibians were categorised as unknown anurans and treated as a separate group in the dietary breadth analysis. Using these family-level frequencies we calculated Levins' measure of niche breadth (Levins 1968) based on the equation $B=1 / \sum p i^{2}$ breath and $p i$ is the proportion of individuals consuming a particular prey type) and standardised this measure to range between zero and one(Lewis et al. 2006) using the equation $B_{\mathrm{A}}=(B-1) /(n-1)$, where $B_{\mathrm{A}}$ is standardised niche breadth, and $n$ is the total number prey types consumed. We compared class-level frequencies of prey items across the diets of cape cobras from different biomes using a $\mathrm{X}^{2}$ contingency analysis. Due to limitations in sample size in some biomes, we restricted our comparison of diets to the fynbos, savanna, thicket and succulent and Nama-Karoo biomes. Additionally, using $\chi^{2}$ contingency analysis, we compared classlevel frequencies of prey items in the diets of animals from winter, summer and yearround rainfall regions. Finally, we used one-way ANOVAtotest the hypothesis that different preytype classes were consumed by different sized snakes.

\section{Results}

We gathered 101 feeding records for cape cobras (Table 1; Online supplementary material S1). These included 44 records from dissected museum specimens, 35 literature records, and 22 records from citizen science contributions (online supplementary material S2), five of which were not detected by other methods. We confirmed the presence of birds in the diet of cape cobras ( $n=10$; including eggs and chicks). Additionally, we recorded 35 instances of cape cobras consuming other snakes. Based on family-level prey frequencies, we estimated Levins' measure of niche breadth as $B=6.57$ which we standardised to $B \mathrm{~A}=0.29$. Among snakes for which we had body size measures $(n=39)$, mean $( \pm$ SD) SVL $(1058 \pm 355 \mathrm{~mm})$ did not differ significantly (ANOVA: $F$ 2,38 $=0.29 ; P=0.74$ ) between snakes that had consumed amphibians $(n=9)$, mammals $(n=22)$, or reptiles $(n=8)$, Fig. 1 . We found no evidence for individual prey classes $\left(\chi^{2}{ }_{12}=13.35 ; P=0.34\right)$ or prey types (ectothermic vs endothermic; $\chi^{2 / 4}=1.78 ; P=0.78$ ) being associated with snakes from specific biomes. Neither did we find an association between either of the sexes and prey classes they consumed $\left(\chi^{2 / 3}=1.63 ; P=0.44\right)$. We assigned 96 records to their associated rainfall region ( $\left.N_{\text {winter }}=17 ; N_{\text {summer }}=48 ; N_{\text {year-round }}=31\right)$ but found no association between rainfall region and prey when prey species were classified at the level of class $\left(\chi^{2 / 6}=2.06 ; P=\right.$ o.91), or as endotherms or ectotherms $\left(\chi^{2 / 2}=0.003 ; P=0.99\right)$. 
Table 1. Summary of diet records for cape cobras (Naja nivea) from the literature, citizen science, and the examination of museum material. See online supplementary material for details.

\begin{tabular}{|c|c|c|c|}
\hline Prey & $\begin{array}{l}\text { No. of } \\
\text { records }\end{array}$ & $\begin{array}{l}\text { Percentage of } \\
\text { records }(\%)\end{array}$ & Sources \\
\hline Amphibians & 18 & 17.8 & $\begin{array}{l}\text { De Waal 1978; Haacke et al. 1993; Shine et al. } \\
\text { 2007; citizen science; this study. }\end{array}$ \\
\hline Birds & 10 & 9.9 & $\begin{array}{l}\text { Skead 1950, Maclean 1973; Friedl \& Klump 1999; } \\
\text { Lloyd et al. 2001; Covas 2002; Nalwanga et al. } \\
\text { 2004; Phelps 2007; citizen science. }\end{array}$ \\
\hline Mammals & 30 & 29.7 & $\begin{array}{l}\text { De Waal 1978; Phelps 2007; Shine et al. 2007; } \\
\text { citizen science; this study. }\end{array}$ \\
\hline Reptiles & 43 & 42.6 & See below \\
\hline (Snakes) & 35 & 34.7 & $\begin{array}{l}\text { Broadley 1972; De Waal 1978; Haacke et al. 1993; } \\
\text { Phelps 2007; Shine et al. 2007; Maritz 2013; } \\
\text { citizen science; this study. }\end{array}$ \\
\hline (Lizards) & 7 & 6.9 & $\begin{array}{l}\text { Phelps 2007; Shine et al. 2007; citizen science; this } \\
\text { study. }\end{array}$ \\
\hline (Chelonians) & 1 & 1.0 & Haacke et al. 1993. \\
\hline
\end{tabular}

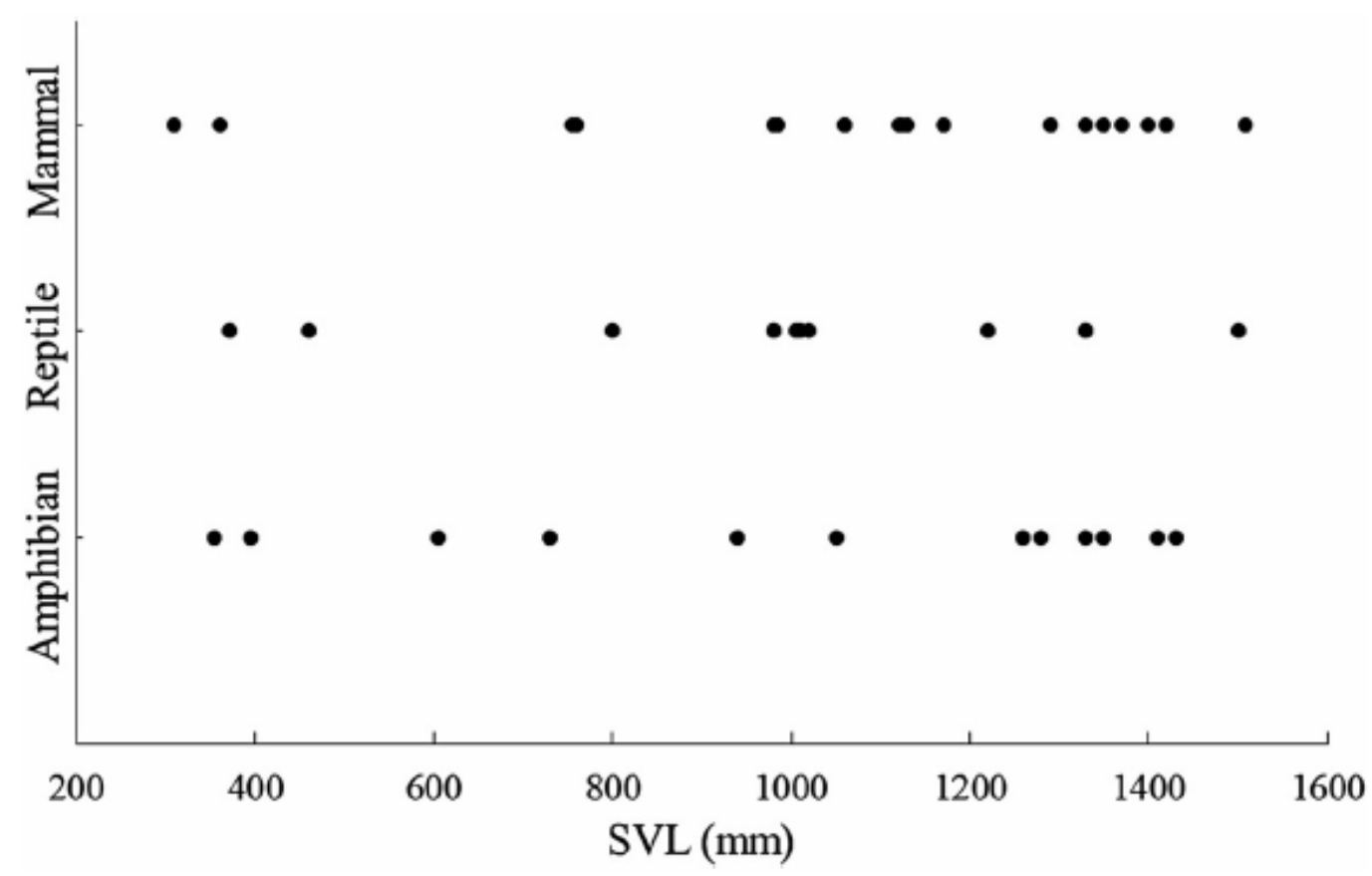

Figure 1. Snout-vent length (SVL; mm) measures for 44 cape cobra (Naja nivea) museum specimens that contained amphibian $(n=12)$, reptilian $(n=11)$, and mammalian $(n=21)$ prey items. 


\section{Discussion}

Our results indicate that cape cobras consume a wide range of vertebrate prey from all four tetrapod classes. Importantly, we show that snakes (including conspecifics) make up a large proportion of cape cobra diets, and that birds, including chicks and eggs are regularly consumed. Our results, combined with the finding of Phelps (2007) that cape cobras will scavenge prey items, suggest a remarkable feeding repertoire, with implications for their trophic placement, potential impacts on prey communities, ecosystem services, intraguild competition and intraspecific interactions.

The diversity of prey types identified in the diets of cape cobras, combined with the absence of any meaningful patterns of broad-scale dietary variation, strongly suggest that cape cobras are generalist predators that feed opportunistically on tetrapods. Although our estimation of dietary breadth suggested a relatively narrow diet (a standardized value close to zero is interpreted as a specialist predator and a value closer to one is regarded as a generalist predator; Lewis et al. 2006), our data suggest that cape cobras are likely to consume any suitably sized tetrapods that they encounter, should the opportunity arise. As such, they are likely to compete directly for food resources with most snakes within the ecosystems in which they occur. In comparison with other southern African snakes, only Duberria and Aparallactus (which prey on molluscs and chilopods respectively; Branch 1998) frequently eat prey not consumed by cape cobras. Although we found no evidence for fish in the diets of cape cobras, other African Naja (such as Naja melanoleuca) are reported to capture and consume fish regularly (Broadley 1983). We suspect that the absence of fish in the diet of cape cobras is an artefact of the low abundance of fish in the arid habitats these snakes inhabit.

Our approach includes some inherent biases. For example, our review likely underestimates the frequency with which amphibians are consumed by cobras (Glaudas et al. 2017) because of the differential detectability of prey types in museum gut contents. Additionally, literature records are necessarily treated as individual feeding events, but several of these records are likely to represent isolated reported cases of relatively widespread feeding behaviour. For example, only a select number of references report cape cobras as predators of sociable weavers. However, close examination of those references, as well as our own field observations, suggest that cape cobras prey extensively on these birds at certain times of the year. Because sociable weavers are widespread within the distribution of cape cobras, this phenomenon is likely to be common. Between 10 and 14 March 2017, we detected ten individual cape cobras in sociable weaver colonies at a site in the Northern Cape Province, South Africa. Of these animals, six showed visible signs of recent feeding and two of these regurgitated sociable weaver chicks and eggs (B. Maritz pers. obs.). Unfortunately, such biases are likely to impact all broad-scale reviews of this type.

Vipers (genus Bitis) are particularly common prey items, accounting for $40 \%(n=14)$ of all snake records. The abundance of vipers in the diet of cape cobras (and likely other subSaharan Naja) could stem from high abundances of vipers in many landscapes. Maritz and Alexander (2012) showed that the diminutive Bitis schneideri occurs at densities of 
approximately 8 individuals $\mathrm{ha}^{-1}$, and a sample of 189 snakes reported from the central Kalahari in Botswana by Broadley (1972) included 134 Bitis caudalis, constituting 70\% of all snakes collected, suggesting a high population density. Although puff adders (Bitis arietans) are widely perceived to occur at high densities, this remains to be rigorously quantified. Cape cobras are actively foraging species (Shine et al. 2007) that can easily catch up with ambush foraging species, such as Bitis spp., making individuals of these species particularly susceptible to foraging cobras, inflating their abundance in cobra diets.

Predation from generalist predators that consume a wide variety of prey is associated with prey population stabilisation through suppression of numerically abundant prey (Closs et al. 1999). In doing so, such predators may perform important ecological functions by preventing prey population eruptions (Closs et al. 1999). Cape cobras are already thought to be important top-down regulators of sociable weaver ( $P$. socius) populations (Covas 2002), and their generalist diet suggests that they are likely able to endure a weaver population crash. Additionally, the consumption of large numbers of rodents, including introduced Rattus, suggest that cape cobras may offer an important ecosystem service through the suppression of problem rodent populations. Although cape cobras are known to persist in anthropogenically transformed habitats, the magnitude of their impact on problem animal populations remains to be quantified.

Our data suggest that cape cobras probably act as intraguild predators (see Arim \& Marquet 2004) of several other snake competitors. For example, cape cobra diet appears to overlap extensively with puff adders that consume rodents, birds, amphibians and squamate reptiles (Glaudas et al. 2017). However, puff adders are frequently consumed by cape cobras, suggesting a strong intraguild competitive advantage where these species co-occur. Similarly, cape cobras and boomslang (Dispholidus typus) both consume large numbers of sociable weaver chicks and eggs where they occur together (Covas et al. 2008; Smith 2016). In these systems, the two species are likely to compete for both food resources as well as the structural resources offered by sociable weaver colonies. We predict that future observations will reveal evidence of the consumption of boomslang by cape cobras. Our study provides the basis for several testable hypotheses and in doing so, it highlights the value of natural history studies as hypothesis generation exercises. Despite this inherent value, studies such as ours are becoming increasingly rare, even though the basic biology of many African reptiles remains poorly documented. In this light, we unashamedly suggest renewed vigour in the reporting, quantification and synthesis of foundational biology of African reptiles.

\section{Acknowledgments}

We thank the University of the Western Cape and the National Research Foundation (unique grant number 99186). D. Hamerton, J. Opperman, L. Mahlangu, L. Mashinini, W. Conradie and B. Wilson provided access to specimens in their care. T. Kearney, A. Engelbrecht, W. Conradie, and B. Wilson assisted with identification of specimens. R. Maritz, B. Wilson and $\mathrm{H}$. Fölscher assisted in the examination of museum material. Special thanks to R. 
Shine for kindly providing the raw data of his study. We thank the numerous citizen scientists for their photographic records on social media.

\section{Supplemental material}

Supplemental data for this article can be accessed at https://doi.org $10.1080 / 21564574.2017 .1388297$. 


\section{References}

ARIM, M. \& P.A. MARQUET. 2004. Intraguild predation: a widespread interaction related to species biology. Ecol Lett. 7(7): 557-564.

BARLOW, A., C.E. POOK., R.A. HARRISON \& W. WÜSTER 2009. Coevolution of diet and prey-specific venom activity supports the role of selection in snake venom evolution. Proc $\mathrm{R}$ Soc Lond B Biol Sci. 276(1666): 2443-2449.

BRANCH, W.R. 1998. Field guide to snakes and other reptiles of southern Africa. Struik Nature, Century City, South Africa.

BROADLEY, D.G. 1972. The horned viper in the central Kalahari. Botswana Notes and Records 4: 263. BROADLEY, D.G. 1983. Fitzsimons' snakes of southern Africa. Delta Books, Johannesburg, South Africa.

CLOSS, G.P., S.R. BALCOMBE \& M. J. SHIRLEY. 1999. Generalist predators, interaction strength and food-web stability. Adv Ecol Res. 28: 93-126.

COVAS, R. 2002. Life history evolution and cooperative breeding in the sociable weaver. $\mathrm{PhD}$ Thesis, Faculty of Science, University of Cape Town, Cape Town, South Africa. 135 pp.

COVAS, R., M.A. DU PLESSIS \& C. DOUTRELANT. 2008. Helpers in colonial cooperatively breeding sociable weavers Philetairus socius contribute to buffer the effects of adverse breeding conditions. Behav Ecol Sociobiol. 63(1): 103-112.

DALTRY, J.C., W. WÜSTER \& R.S. THORPE. 1998. Intraspecific variation in the feeding ecology of the crotaline snake Calloselasma rhodostoma in Southeast Asia. J Herpetol. 198205.

DE WAAL, S.W.P., 1978. The Squamata (Reptilia) of the Orange Free State, South Africa (No. 11). Nasionale Museum.

FRIEDL, T.W. \& G.M. KLUMP. 1999. Determinants of male mating success in the red bishop (Euplectes orix). Behav Ecol Sociobiol. 46(6): 387-399.

GLAUDAS, X., T. KEARNEY \& G.J. ALEXANDER. 2017. Museum specimens bias measures of snake diet: a case study using the ambush-foraging puff adder (Bitis arietans). Herpetologica 73(2): 121-128. GREENE, H.W. 1997. Snakes: The evolution of mystery in nature. University of California Press, Berkeley.

GREENE, H.W. 2005. Organisms in nature as a central focus for biology. Trends Ecol Evol. 20(1): 23-27.

HAACKE, W.D., H. KUBIERSKE, T. ULBER, M.F. BATES, Q. HAHNDIEK, G.V. HAAGNER, B.J. LESLIE, D.G. BROADLEY, A.L. DE VILLIERS, D.R. MORGAN \& J.J. HERHOLDT. 1993. Geographical Distribution. The Journal of the Herpetological Association of Africa 42: 4043.

HOCKEY, P.A.R., W.R.J. DEAN \& P.G. RYAN. 2005. Roberts Birds of Southern Africa. 7th edn. The Trustees of The John Voelcker Bird Book Fund, Cape Town, South Africa.

KGADITSE, M. 2016. The evolution and diversification of diet in elapids. MSc Thesis, School of Animal, Plant \& Environmental Sciences, University of the Witwatersrand, Johannesburg, South Africa. 90 pp.

LEVINS, R. 1968. Evolution in Changing Environments: Some Theoretical Explorations. Monographs in Population Biology, Number 2. Princeton, New Jersey, USA: Princeton University. 
LEWIS, S.B., K. TITUS \& M.R. FULLER. 2006. Northern Goshawk diet during the nesting season in southeast Alaska. J Wildl Manage. 70(4): 1151-1160.

LLOYD, P., R.M. LITTLE \& T.M. CROWE. 2001. The breeding biology of the Namaqua Sandgrouse, Pterocles namaqua. Ostrich-Journal of African Ornithology 72(3-4): 169-178.

MACLEAN, G.L. 1973. The sociable weaver, part 4: predators, parasites and symbionts. Ostrich-Journal of African Ornithology 44(3-4): 241-253.

MARAIS, J. 2004. A complete guide to the snakes of southern Africa. Struik Nature, Century City, South Africa.

MARITZ, B. 2013. Bitis arietans predation. African Herp News 59: 21-28.

MARITZ, B. \& G.J. ALEXANDER. 2012. Population density and survival estimates of the African viperid, Bitis schneideri. Herpetologica 68(2): 195-202.

MARITZ, B., L. VERBUGT, A. COETZER, T. PING, R.A. MARITZ, G. NICHOLAU, N. PARRY \& J. BOYCE. Facebook group: Predation records-reptiles and frogs. https://web.facebook.com/groups/ 888525291183325/ [Accessed 1 August 2017].

NALWANGA, D., P. LLOYD, M.A., DU PLESSIS \& T.E. MARTIN. 2004. The influence of nest-site characteristics on the nesting success of the Karoo Prinia (Prinia maculosa). Ostrich-Journal of African Ornithology 75(4): 269-274.

PHELPS, T. 2007. Observations of the Cape cobra, Naja nivea (Serpentes: Elapidae) in the De Hoop Nature Reserve, Western Cape Province, South Africa. Herpetological bulletin 99: 29-35.

RODRÍGUEZ-ROBLES, J.A. 2002. Feeding ecology of North American gopher snakes (Pituophis catenifer, Colubridae). Biol J Linn Soc Lond. 77(2): 165-183.

SHINE, R., W.R. BRANCH, J.K. WEBB, P.S. HARLOW, T. SHINE \& J. S. KEOGH. 2007. Ecology of cobras from southern Africa. J Zool (Lond). 272(2): 183-193.

SCHULZE, R.E. 1997. South African atlas of agrohydrology and climatology. Water Research Commission, Pretoria, South Africa. Report TT 82/96.

SKEAD, C. J. 1950. A study of the African hoopoe. International Journal of Avian Science 92(3): $434-461$.

SMITH, C. C. D. 2016. Quantifying the foraging ecology of the Boomslang (Dispholidus typus). Hons Thesis, Department of Biodiversity and Conservation Biology, University of the Western Cape, Bellville, South Africa. 17 pp. 